\title{
Recent Trends in Mentoring and Counseling Programs for Talented Students in KSA Schools
}

\author{
Saeed Moshabab Ali Al-Qahtani \\ Saudi Ministry of Education, Saudi Arabia
}

\begin{abstract}
The objective of the present study is to learn about latest trends in the orientation and guidance of talented students in Saudi Arabian schools, where the literature on the implementation and application of mentor-ship theories has been reviewed in a variety of modern ways. The study used the analytical approach, where recent studies have been analyzed to guide talented students. The study concluded that there is an urgent need to design qualitative demonstration programs based on emotional, social and pedagogical needs that consider the extraordinary mental capacities of talented students. It should also use appropriate indicative methods suited to the objectives to be achieved, and the study emphasized the importance of covering various stages of development. The study also recommended that global programs should be familiarized with the guidance and simulation of talented student.
\end{abstract}

\section{Introduction}

Talented students need guided services in quality method, because they have high mental abilities. Educational institutions have sought attention to that category of students and take in consideration the social, psychological and mental needs of them. And provide for the individual and collective guidance programs commensurate with the stages of growth, according to the theories of modern guidance. We must as educationalists and specialists in the upbringing of talented people to take most gifted students to safety. And to guide them academically, socially and psychologically and preparation of programs that suited to the psychological characteristics of them. Especially that, Global initiatives in the development of quality standards for gifted programs focused on several criteria, including psychological and social guidance [3].

Some people think that gifted students do not need psychological guidance and confined the mental health in the presence of talent, and this logic is not true; they need psychological guidance and specialized programs that guide them to achieve psychosocial harmony. "Gifted children do not just think differently than their peers. But feel different and strange than them" [7].
There are aspects that must be considered in the process of mentoring gifted people: social environmental aspects, family roles, and self-aspects. These are the energies and personality traits that generate and direct behavior, such as positive selfconcept, personal and social harmony, Additional [11].

In this regard, the interest of psychology and education in gifted and disabled persons, in terms of their interest in discovering and identifying their psychological, social, ethnic and physical characteristics, to prepare ways of caring for them and to invest their abilities and preparations for the benefit of the members of society.

\section{Research problem}

Saudi Arabia, in its patronage of talented people, is moving in a flexible direction that is based on mentoring and counseling gifted students to meet their special needs, both in regular schools and centers for the care of talented students.

The needs of gifted students have not been considered in terms of guidance and psychological counseling in the planning of programs and the preparation of curricula for many reasons and false beliefs. However, modern educational trends have emphasized the need to take the needs of the gifted psychologically into consideration as the needs of the other categories of people with special needs are taken into consideration.

Gifted students - from primary to high school need help in issues of self-understanding, social and family issues, as well as problems associated with education and professional life. Many professionals interested in educating gifted people strongly support the idea that mentoring is essential for growth And that counseling should be a complementary component of all gifted programs, and as a general rule, the greater the talent, the greater the consultation required [2].

Social and emotional needs are important conditions that must be met for positive adjustment, which are related to personal harmony, the happiness of the individual, relationships with others and high attainment. They also have to do with selfunderstanding, understanding of others, social action, expression of emotions, 
All gifted children need at least three requirements to meet their social and emotional needs. These include providing students with the opportunity to learn with others of similar interests, abilities, and motivation, the need for an appropriate level of challenge in the formal classroom, and flexible gradation in the curriculum [10].

Hence, there is a need for a modern pedagogic and psychological orientation in the field of caring for talented students in schools and programs. These developmental and preventive extension services help to better empower talented students.

\section{Research Questions}

The current research seeks to answer the following questions:

Question 1: What are the current trends in guiding and mentoring talented students in schools in Saudi Arabia?

Question 2: What are the methods of implementing the modern guidance and counseling in schools of Saudi Arabia?

\section{Research Aims}

This research aims to achieve the following objectives:

1 - Shed light on the current trends in counseling and guidance of talented students in the field of education in schools in the Kingdom Saudi Arabia.

2- Demonstrating the methods of implementing the counseling process in the educational field in the schools of the Kingdom of Saudi Arabia.

\section{Research Importance}

The importance of the current research is clear from two theoretical and practical aspects:

a. Theoretical Importance:

1. It deals with a very important topic, the subject of guidance.

2 - The study focuses on the category of gifted and they are the most needed for the counseling process.

3 - Research in the alert to the importance of counseling and guidance in the care of gifted students during the planning and implementation of programs.

B. Practical importance:

1- This research comes in line with the latest trends in the Kingdom of Saudi Arabia, to achieve an ambitious vision aimed at expanding the application of e-learning to cope with the acceleration of scientific progress.

2 - Apply modern trends in counseling and guidance for gifted students in the field of education.

\section{Research terms}

\subsection{Orientation}

A group of psychological services offered to individuals in their practical lives to help them choose the most appropriate in all areas of interest to them such as professional, family and educational fields [12].

\subsection{Guidance}

The process of helping the individual in drawing up educational plans that fit his abilities, tendencies and goals and choose the type of study and appropriate curricula and study materials that help him to discover the educational possibilities and help him to succeed and diagnose the educational problems and treatment to achieve his educational consensus in general [4].

\subsection{Guidance and Counseling}

A process of building that aims to help the individual to understand himself, study his personality, know his experiences, identify his problems, develop his potentials and solve his problems in the light of his knowledge and desire to reach and define clear goals [13].

\subsection{Talented Student}

Definition of the Ministry of Education in the Kingdom of Saudi Arabia:

Gifted students are defined as students who have extraordinary abilities and aptitude, or distinct performance from their peers in one or more areas of society's esteem, especially in areas of mental excellence, innovative thinking, achievement, and exceptional skills and abilities. They need special educational care, which may not be fully integrated into the regular study programs [8].

\section{Methodology}

The research used an analytical descriptive approach, where literature on the implementation and application of theories of guidance and counseling was reviewed.

Search Information Sources:

For the current research sources have benefited from the information contained therein:

1. Reading and reading in the educational literature for the guidance and counseling of talented students.

2. Investigation and analysis of psychological theories related to giftedness. 


\section{Results}

The results of this research were as follows:

- There is an urgent need to pay attention to the psychosocial needs of gifted students that are equivalent to educational needs.

- The tendency to design quality mentoring programs that consider the high mental abilities of gifted students.

- The need to disseminate awareness in diverse ways to talented people, their teachers, and their families.

- Developmental and preventive extension services help to better empower talented students.

\section{Discussion}

Guiding and mentoring talented students: Some believe that talented students do not need mentors because they are smart enough to solve their problems. On the other side they think. The gifted and creative students do not need any special help, Additional guidance because of their high capabilities.

In general, there is a general lack of studies that assess whether talent is highly or not related to the need for guidance. In general, whether these differences exist, the mentor should consider that the emergence of talent is associated with social difficulties, stress, Professional decision making. Also the mentor can create a supportive environment for gifted students by offering group counseling so that the student can resolve certain issues, gain support and support others, and help the students understand and deal with their unique mental, emotional and social needs, and many methods are used in group counseling, such as seminars and training meetings, especially in the implementation of vocational and emotional guidance programs, as well as voluntary work to develop the social aspect, develop selfconcept and develop a sense of responsibility towards society, as well as training in leadership especially in the fields of science, The personal, social and cognitive characteristics of the student so that he can influence and convince others [5].

Psychologists and educators also emphasized the need to guide the gifted child more than the average child, gifted children have distinct abilities in some areas of growth and this excellence in performance makes them with special educational needs are a special challenge for their teachers and their parents, as well as representing sources of tender and a distinct contribution needed by all Human communities. The gifted have problems caused by the family because of the frequent criticism of family relations because of the sense of difference from others

Because of the excellence of gifted students in their personal, behavioral, emotional, educational, leadership and social qualities, they have problems resulting from these features with the school community and the family and even the local community and the work community, so it was necessary to identify their problems and try to find suitable solutions for them guidance, counseling and help them to adapt properly to the community in all its details. And hence emerged the need for the need for educational and psychological guidance in the field of talented.

Objectives of mentoring Gifted students:

- Detecting the child's preparations and evaluating his experiences.

- Child mental health insurance.

- Provide appropriate opportunities for the development of its preparations.

- Adapting the school environment.

- Providing preventive, developmental and therapeutic services [9].

Areas of mentoring gifted students:

1. Religious and moral guidance and counseling: Our Islamic religion is the foundation upon which all the efforts, services and activities of the educational and educational activities offered to our children and students do not go out of their way. The aim of this field is to intensify the efforts to develop the Islamic values and principles of the students and to invest the appropriate scientific means and methods to employ and consolidate these principles and Islamic ethics and translate them into behavioral practices that appear in all the student's actions.

2. Guidance and educational counseling: It is the process of assisting the student in drawing up and defining his educational plans and programs that suit his abilities, preparations, abilities, interests, goals, and aspirations, and choose the type of study that suits him.

3. Guidance and psychological counseling: Psychological guidance is intended to help the student to understand himself and identify the aspects of his personality and abilities and readiness and tendencies and potentials and development and help solve problems to achieve the goals and psychological, educational, social and professional to live healthy psychological sound.

4. Guidance and social counseling: This field is concerned with the growth and social development of the student and his relationship with others and society in general values and habits, norms and social experiences and effects on the student.

5. Guidance and preventive counseling: It is called psychological immunization against psychological and personal problems and disorders. The aim of this field is to educate and enlighten students about the religious, health, psychological or social consequences and consequences that may result from 
some negative practices and actions and to eliminate their causes. Their stages of awareness and enlightenment through seminars, lectures, and publications.

6. Guidance and career counseling: There are talented students who are multi-talented or over the edge of another or do not know their level of talent or do not know that they are truly talented Guidance and counseling is the process of helping the person to choose the scientific field and work commensurate with his tendencies and preparations and abilities and preparation Rehabilitation, enrollment, progress and the best level of compatibility with him [1].

A proposed model for the role of the student guide considering the latest trends in guiding and mentoring talented students:

The role of the student guide in the gifted centers is in no way different from the policy of the educational system in Saudi Arabia. The gifted students are not excluded from the counseling and guidance areas. The fields are fixed for all cases but differ according to the diagnosis as in special education. For example, they need in the educational side what develops the side of educational achievement in addition to the development of the talents they have.

The student guide helps the student to understand himself and knowledge about his abilities and overcome the difficulties he might faces in order to achieve the compatibility of psychological, educational, social and professional to build a personality together in the framework of Islamic teachings and by:

- Preparation of the annual general plan for mentoring programs in the light of instructions.

- To enlighten the talent community with the objectives of counseling and guidance. - Create the necessary capabilities for the indicative work of records and tools.

- The formation of steering committees in accordance with the instructions.

- Implementing development, prevention and treatment programs, and guidance, including:

1. Help the student to use his abilities and preparations to the maximum extent possible.

2. To develop and enhance the positive characteristics of students in light of the principles of the Islamic religion.

3. Develop the student's motivation towards education and raise the level of ambition.

4. Follow-up level of academic achievement.

5. Invest all possible opportunities in the formation and development of positive attitudes among students.

6. Identify students with special talents and abilities.

7. Help students enrolled in gifted programs to adapt to the environment of gifted centers.

8. Defining talent and characteristics of talented students.
9. Discover the twice diagnosis students.

10. Documenting the relationship between the student family and the gifted center.

11. Activating the educational partnership between the gifted center and the public education schools.

12. Work on the nomination and promotion of the scientific orientation of gifted students.

13. Work to deepen the student's awareness of the reality and the problems faced by the educational and social.

14. Instruct talented students to maintain order within the gifted center.

15. Work on the development of extension programs [6].

\section{Conclusion}

The latest trends in counseling and guiding talented students require the intensive care of this group in all aspects of psychological, mental, social and emotional, and the activation of appropriate educational strategies and means. Talent affects the psychological development of the child and his happiness through the relations between the characteristics and manifestations of talent and talent (medium or deep talent) And also to the extent to satisfy the basic needs, talented students special needs special care to enable them to develop their energies and talents as much as possible according to their characteristics and problems and needs of different, and as it is based on the teaching of talented students qualified teachers must also select guides with experience in the field of guidance and knowledge of the characteristics Gifted students and their emotional and social needs to understand their complex and diverse nature and help them overcome their educational, emotional and social problems.

\section{Recommendations}

- Conduct further studies on this subject.

- Prepare qualified and specialized counselors.

- Benefit from the experiences of developed countries.

\section{References}

[1] Chen, C. P., \& Wong, J. (2013). Career counseling for gifted students. Australian Journal of Career Development, 22(3), 121-129.

[2] Chan, D. W. (2003). Assessing adjustment problems of gifted students in Hong Kong: The development of the student adjustment problems inventory. Gifted Child Quarterly, 47(2), 107-117.

[3] Wood, S. (2010). Best practices in counseling the gifted in schools: What's really happening? Gifted Child Quarterly, 54(1), 42-58. 
[4] Elijah, K. (2011). Meeting the Guidance and Counseling Needs of Gifted Students in School Settings. Journal of School Counseling, 9(14), n14.

[5] Kerr, B. (1991). A handbook for counseling the gifted and talented. American Association for Counseling and Development, 5999 Stevenson Ave., Alexandria, VA 22304 (Order No. 72030: \$29.95).

[6] Ishak, N. M., \& Bakar, A. Y. A. (2014). Counseling services for Malaysian gifted students: An initial study. International Journal for the Advancement of Counselling, 36(4), 372-383.

[7] Milgram, R. M. (Ed.). (1991). Counseling gifted and talented children: A guide for teachers, counselors, and parents. ABC-CLIO.

[8] Colangelo, N. (2002). Counseling Gifted and Talented Students.

[9] Moon, S. M., \& Reis, S. M. (Eds.). (2004). Social/emotional issues, underachievement, and counseling of gifted and talented students. Corwin Press.

[10] Neihart, M. (2006). Services that meet social and emotional needs of gifted children. Designing services and programs for high ability learners: A guidebook for gifted education, 112-124.

[11] Al Farsi Hakam, S. H., Juma, N., \& Issan, S. (2018). Activating Communication Between School Principals And Supervisors In Basic Education In The Sultanate Of Oman. International Journal of Engineering Technologies and Management Research, 5(8), 54-63.

[12] Ziegler, A., \& Heller, K. A. (2000). Conceptions of giftedness from a meta-theoretical perspective.International handbook of giftedness and talent, 2, 3-21.

[13] Banat, S. M., Soua'd M, G., \& Barahmeh, M. S. (2013). The Reality of Counseling Services Provided by the School Counselor for Gifted and Talented Students in the Jordanian Government School. Journal of Educational and Psychological Studies [JEPS], 7(2), 151-166. 